\title{
Adaptive Significance of Small Body Size under Poor Socio-economic Conditions in Southern Peru
}

\author{
A. ROBERTO FRISANCHO, JORGE SANCHEZ," DANILO \\ PALLARDEL $^{-1}$ AND LIZANDRO YANEZ ${ }^{1}$ \\ Center for Human Growth and Development and Department of \\ Anthropology, The University of Michigan, \\ Ann Arbor, Michigan 48104
}

KEY WORDS Adaptation S Survival - Body size $\cdot$ Peru.

\begin{abstract}
The relationship of variations in parental body size to offspring survival has been studied in a population of poor socio-economic conditions ("Barriada") in the southern highland of Peru. Parents of small body size, especially mothers, had significantly greater per cent offspring survival than parents with larger body size. In other words, the offspring survival effectiveness of subjects of small body size was greater than that of subjects of large body size. It is postulated that the greater offspring survival effectiveness associated with small parental body size may reflect possible adaptive responses to poor socio-economic conditions.
\end{abstract}

Population variations in body size represent one of the most important parameters in the study of ongoing evolution of man. There is considerable evidence indicating that human variation in body size is the result of the interaction of environmental and genetic factors at both the developmental and adult stages. Therefore, it is quite possible that population differences in body size may be traced to the relationship of variations of parental body size to offspring survival. One productive way to study possible variations in survival and mortality is under conditions of environmental stress. Poor socioeconomic conditions, because they are usually associated with nutritional limitation (Scrimshaw and Gordon, '68), represent an environmental stress which is known to influence body size during growth and adulthood (Frisancho, Garn and Ascoli, 70). In order to determine possible variations in offspring survival associated with variations in parental body size, we have conducted an anthropometric and demographic study in a population of poor socio-economic status in southern Peru. The results, reported in this paper, provide evidence of a significant association between high offspring survival and small parental body size under poor socio-economic conditions.

\section{MATERIALS AND METHODS}

\section{The population}

In recent years, both highland and lowland rural populations have migrated to the main urban centers. Because of the scarcity of housing facilities, these populations settled in the outskirts of the main cities, forming new settlements currently referred to as "Barriadas" (Graham and Morales, '63; Mangin, '67; Pollitt and Ricciuti, '69).

The data presented in this study were collected over a six month period from January to June 1971 from a "Barriada" population living in the outskirts of the city of Cuzco, Peru. This "Barriada" was composed of four subdivisions "Viva el Peru," "Ollanta," "Velasco Alvarado," and "Manco Capac") and was established in 1967 (4 years prior to the date of the present study). According to the office of "Desarrolo Comunal of Cuzco," the "Barriada" consisted of a total of 500 households. Although accurate information was available on only a limited number of the families, their economic situation is one of marked poverty characterized by the lack of sewage, water, and electricity, and housing which consisted mostly of one or

1 Programa Academico de Anthropologia, Universidad Nacional del Cuzco, Peru. 
two adobe rooms per household with a bare minimum of furniture.

\section{Reproduction: Offspring viability}

A total of 190 heads of household were interviewed by the authors and several assistants to determine the general reproductive characteristics and offspring viability of the population. Information on total number of children born, total number of children dead (including still births and abortions), and total number of children alive was obtained. From these data, the per cent offspring survival (POS) was calculated as follows:

Per cent offspring survival (POS) $=$ $\frac{\text { Total Children Alive }}{\text { Total Children Born }} \times 100$

In addition, from information gathered on age at death of children of the "Barriada," mortality rates were calculated according to standard demographic procedures for the following categories: Infant mortality (deaths under 1 year of age per 1000 live births), toddler mortality (deaths between 1 and 5 years of age per 1000 live births), and post-childhood mortality (deaths between 6 and 19 years of age per 1000 live births).

\section{Anthropometry}

of the 190 families interviewed, complete anthropometric measurements were taken of 290 adult subjects (145 husbands and their respective wives) ranging in age from 20 to 70 years. The measurements included assessment of weight, stature, biacromial diameter, chest circumference (in males only), upper arm circumference, and skinfold thickness at the triceps and subscapula. These were calculated according to standard procedures (Weiner and Lourie, '69). The upper arm muscle circumferences (Jelliffe and Jelliffe, '69) were also calculated. Tests of replicability of measurements in a sub-sample of 50 subjects gave correlations in excess of 0.95 .

\section{Analysis}

First, all subjects who produced children were separated into either short or tall groups, depending upon whether their stature was greater than or less than the mean stature for their sex. In females the average stature was $148 \mathrm{~cm}$ and in males $160 \mathrm{~cm}$. Because there was no association between age and stature in either sex, we used as the cutoff point the average stature of the whole sample. Second, because the per cent offspring survival, weight, and body composition change with age, the comparison of per cent offspring survival of the short and tall groups was made through a one-way analysis of covariance. In this manner, the mean per cent offspring survival of the short parents was adjusted for age, weight, and body composition and was compared to the per cent offspring survival (adjusted in the same way) of the tall group. The resulting regression equations were also tested for statistical differences.

\section{RESULTS}

As indicated by the information received from questionnaires, $93 \%$ of the 190 heads of household were Quechua Indians who came from rural areas and only $7 \%$ were city natives born in the city of Cuzco. The average length of residence in the city of Cuzco prior to settlement in the "Barriada" was 8.5 years, and the length of residence in the Barriada itself averaged 2.9 years. The average years of schooling was 3.3 years for males and 2.5 years for females. Only $46 \%$ of the families received medical attention when sick.

In table 1 , it can be seen that the mean number of offspring born per mother who completed her reproductive period (45 to 70 years) was 7.23 . Of this, about $37 \%$ had died leaving $63 \%$ alive at the time of this study. Table 1 also shows that the childhood mortality (deaths under the age of 5 years per 1000 live births) was about 286, while the post-childhood mortality (deaths between 6 and 19 years) was only 20. Male mortality at all three periods was systematically greater than that of females. The infant, toddler, and childhood mortality in the "Barriadas" was nearly twice that of the city of Cuzco itself. However, evidence of childhood malnutrition, such as Kwashiorkor, marasmus, nutritional edema, and related manifestations, were not observed among this population. Analysis of the causes of 
TABLE 1

Reproductive and mortality characteristics in a "Barriada" population of the city of Cuzco based on questionnaires administered to 190 heads of household

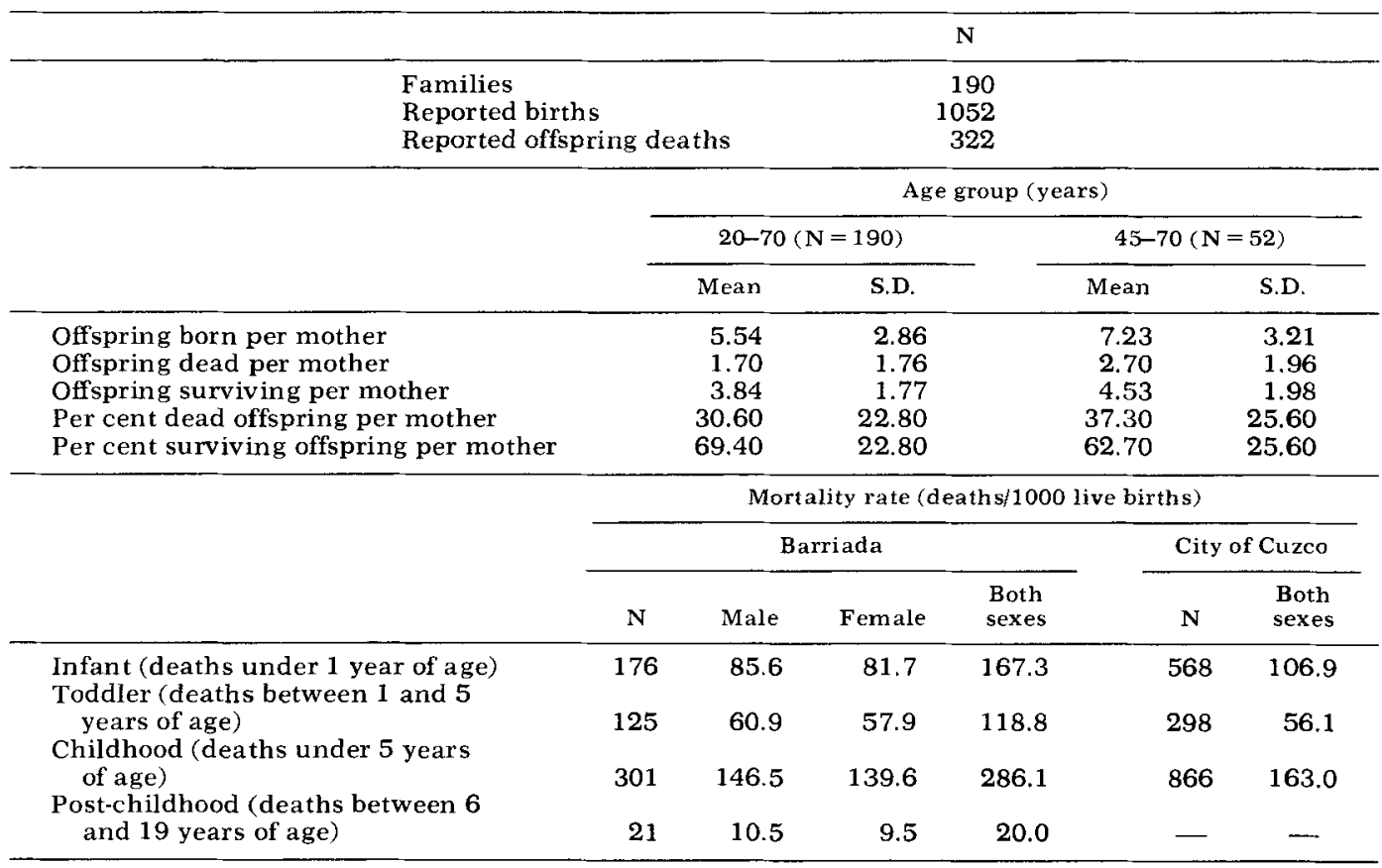

deaths indicated that only 16 were born dead, and 18 were aborted. Maternal stature was not related to any of these deaths. In other words, both tall and short women had approximately the same proportion of still births and abortions.

As indicated by the analyses of covariance presented in table 2 , the per cent offspring survival of short mothers adjusted for age was 78.80 and the comparable value for tall mothers was 70.89 $(p<0.05)$. The per cent offspring survival of short mothers adjusted for both age, skinfolds and arm muscle was 79.50 and $69.84(p<0.01)$ for tall mothers. When the offspring survival was adjusted for variations in age and all the anthropometric measurements, that of short mothers still significantly $(p<0.01)$ exceeds that of tall mothers. In fathers, the difference in per cent offspring survival between the short and tall groups is not well defined. The per cent offspring survival adjusted for age of short fathers was 74.01 and 70.50 for tall fathers $(p<0.10)$. Adjustment for variations in weight, biacromial diameter, and body composition did not appreciably change the difference in per cent offspring survival.

Regression equations describing the relationship between per cent offspring survival and age were calculated for the short and tall parents. As illustrated in figure 1 , at a given age the short mothers had a significantly $(p<0.01)$ greater per cent offspring survival than tall mothers. In other words, and indicated by the similar coefficients for age, the greater per cent offspring survival of the short mothers is not due to differences in age. On the other hand, among males, the regression analysis (not shown here) indicated that the relationship between offspring survival and age in the short fathers was not well differentiated from that of the tall fathers.

In order to test the possibility of predicting the per cent offspring survival from age and all the anthropometric measurements, multiple regression techniques were employed. As shown in table 3, in 


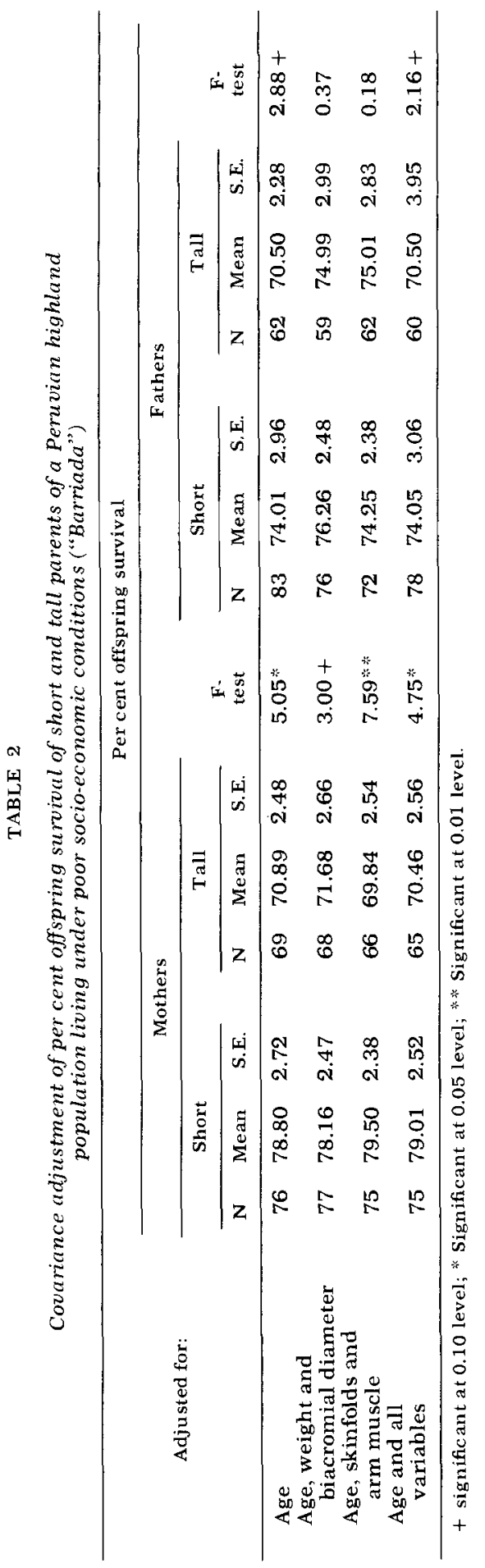

mothers the most important contributors to variation in per cent offspring survival were height, age, and, to a less extent, weight and biacromial diameter. In fathers, age and biacromial diameters appear to be the most important contributors to variation in per cent offspring survival. However, despite these apparent differences the predictive efficiency of the regression equation, as shown by the similar standard error $(\mathrm{SE}=20.48$ in mothers and $\mathrm{SE}=21.49$ in fathers), were nearly the same in both mothers and fathers.

\section{DISCUSSION}

As learned from the general and demographic characteristics, the population under study lived under very poor socioeconomic conditions. Analyses of mortality rates and comparison to those of the main urban population of Cuzco indicated that the childhood mortality in the "Barriada" population was extremely high. This high childhood mortality probably reflected the influence of the poor socioeconomic conditions, as has been seen in other populations (Cravioto and DeLicardi, '68; Scrimshaw and Gordon, '68; Hoff, '68). Furthermore, as in other populations (Yerushalmy, Berg, Erhardt, and Jacobziner, '65; Hunt, '66; Wolanski, '70), the childhood mortality was greater in the males than in the females.

The present study demonstrates that high offspring survival is significantly associated with small body size of the mother and, to a lesser extent, with that of the father. While in upper socio-economic conditions, tall women have a greater offspring survival effectiveness than short women, as indicated by the incidence of premature births, perinatal deaths, still births and abortions (Bresler, '62; Thompson and Belewicz, '63; Thompson, '66), in poor socio-economic conditions the offspring survival effectiveness of tall women is lower than that of short women (Thompson, '66). Indeed, Thompson states that "it may be that women with relatively low growth potential are better adapted to a poor environment than those who grow fast and become tall" (p. 211).

Similarly, Garrow and Pike ('67), after follow-up studies on the effects of malnutrition and nutritional supplementation 


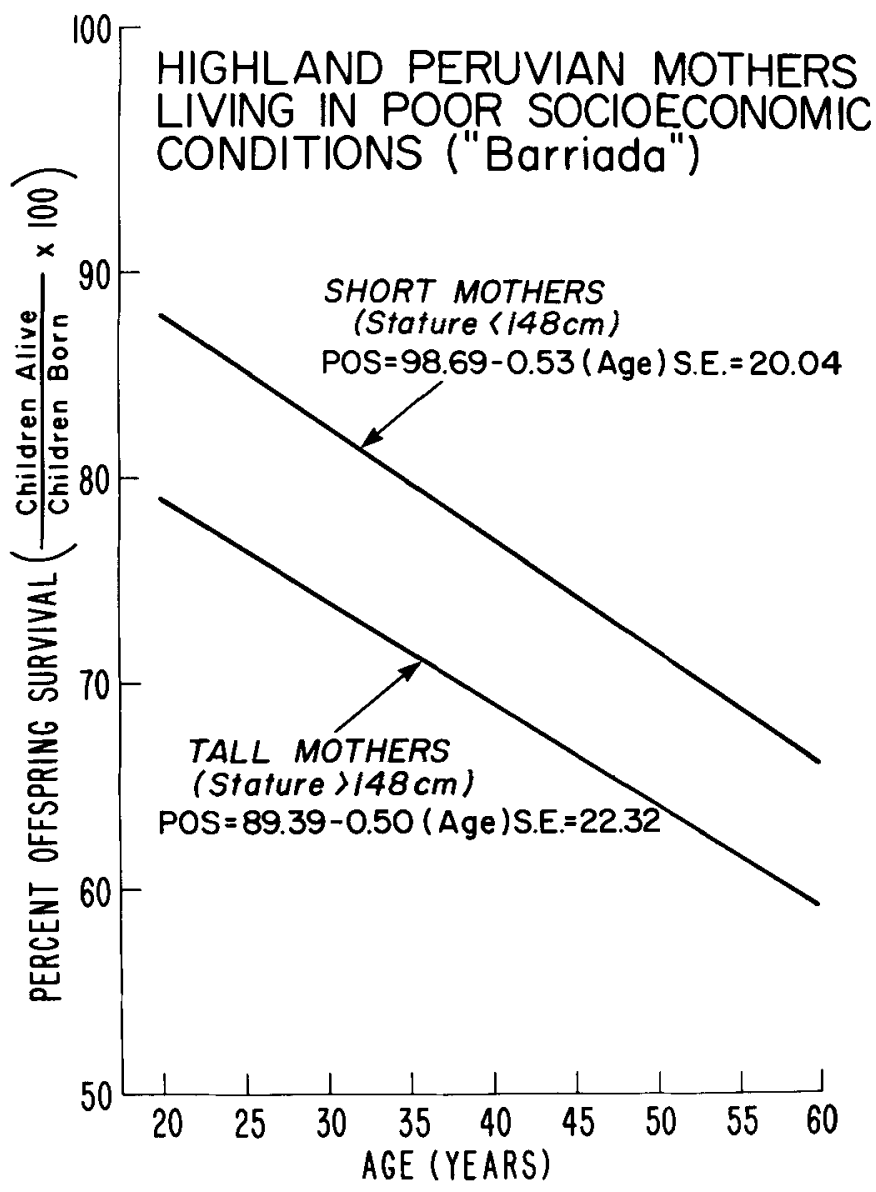

Fig. 1 Relationship between offspring survival and age among short and tall mothers living under poor socio-economic conditions in southern Peru. Short mothers have a greater per cent offspring survival than their tall counterparts.

TABLE 3

Prediction of per cent offspring survival (POS) from age and anthropometric measurements of mothers and fathers of a Peruvian highland population living under poor socio-economic conditions ("Barriada")

\begin{tabular}{ccc}
\hline & \multicolumn{2}{c}{ Regression equation } \\
\hline Mothers & $\mathrm{N}=140$ & $\mathrm{POS}=264.35-1.23(\mathrm{Ht})-0.55(\mathrm{~A})-0.40(\mathrm{Wt})+0.40(\mathrm{BD})$ \\
& & $-0.18(\mathrm{~S})+0.27(\mathrm{AM}), \mathrm{S.E} .=20.48$ \\
Fathers & $\mathrm{N}=140$ & $\mathrm{POS}=123.61+0.11(\mathrm{Ht})-0.57(\mathrm{~A})-0.29(\mathrm{Wt})-0.57(\mathrm{BD})$ \\
& & $-0.22(\mathrm{~S})-0.16(\mathrm{AM}), \mathrm{S} . \mathrm{E} .=21.49$ \\
\hline
\end{tabular}

$A$, age; AM, upper arm muscle circumference; $B D$, biocromial diameter; $\mathrm{Ht}$, height; $\mathrm{S}$, sum of triceps and scapula skinfolds; Wt, weight.

on growth of Jamaican children, concluded that "the child whose genetic make-up is such that he would grow very rapidly if well-fed, will suffer more on a restricted diet than one with more modest demands." (p. 4). Widdowson ('68), through animal experimental studies, indicated that one of the causes for the 
greater mortality of males on a restricted diet is that "their nutritional requirements are larger, so that the same small allowance of protein or calories given to males and females creates a greater deficiency in the males. This is certainly true in rats, and male rats undernourished by being given the same inadequate ration of food as females, "suffer greater deprivation" (p. 232).

In previous studies, we have postulated that the maintenance of slow growth rate resulting in small body size may be adaptive under poor nutritional conditions (Frisancho, Garn and Ascoli, '70). A similar hypothesis has also been advanced by other researchers (Malcolm, '69, '70; Adrianzen, '71; Stini, '72a,b; Garn, Nagy, Poznanski and McCann, '72; Thomas, 72).

In summary, there is considerable evidence supporting the hypothesis that small body size is more adaptive to poor socioeconomic situations or to conditions of dietary restriction (protein or calories) than large body size, due presumably to the lower caloric or nutritional requirements for growth and maintenance. Therefore, it is quite possible that the high offspring survival effectiveness (indicated by the high per cent offspring survival) associated with small parental body size may reflect developmental adaptive responses to poor socio-economic conditions in the "Barriada." Since there was no relationship found, in the present study, between maternal stature and abortions (or stillbirths), the greater per cent offspring survival of the short mothers may not be related to variations in fetal deaths. However, it is possible that the potential non-survivors of the short mothers are eliminated during early prenatal development in the form of abortions, but because abortions occur during the first trimester of pregnancy, it is quite difficult to measure its actual frequency. Therefore, if abortions are influential in producing the difference in offspring survival, it cannot be properly quantified.

While this study presents evidence of higher offspring survival associated with small parental body size, it must be emphasized that in order to advance these findings as an explanation of population variation in body size, further studies with larger sample sizes are required. Therefore, prospective studies of offspring survival, neonatal mortality by birth weight, and growth in relation to parental body size in populations characterized by large and small adult body size living under contrasting but ecologically stable environmental conditions are imperative before any extrapolations to other populations can be made.

\section{ACKNOWLEDGMENTS}

This study was supported in part by grant GS-37542X of the National Science Foundation and by research funds from the University of Michigan. The authors wish to thank the people of the participating "Barriadas" for their cooperation, without which this study would not have been possible. We gratefully acknowledge the competent and enthusiastic assistance of the Junior and Senior students of anthropology at the National University of Cuzco. Margery Serling and Lenny Greenfield are acknowledged for their assistance in data analyses and manuscript preparation.

\section{LITERATURE CITED}

Bresler, J. B. 1962 Maternal height and the prevalence of stillbirths. Am. J. Phys. Anthrop., 20: $515-517$.

Cravioto, J. C., and E. R. DeLicardi 1968 Intersensory development of school-age children. In: Malnutrition, Leaming, and Behavior. N. S. Scrimshaw and J. E. Gordon, eds. The M.I.T. Press, Cambridge, Massachusetts, and London, England.

Frisancho, A. R., S. M. Garn and W. Ascoli 1970 Childhood retardation resulting in reduction of adult body size due to lesser adolescent skeletal delay. Am. J. Phys. Anthrop., 33: 325-336.

Garn, S. M., J. M. Nagy, A. K. Poznanski and M. B. McCann 1972 Size reduction associated with brachymesophalangia-5, a possible selective advantage. Am. J. Phys. Anthrop. 37: 267-270.

Garrow, J. S., and M. C. Pike 1967 The longterm prognosis of severe infantile malnutrition. Lancet, $1: 1-4$.

Graham, G. G., and B. Adrianzen T. 1971 Growth, inheritance and environment. Pediat. Research, 5: 691-697.

Graham, G, G, and E. Morales 1963 Studies in infantile malnutrition. Nature of the Problem in Peru. J. Nutrition, 79: 479-487.

Hoff, C. 1968 Reproduction and viability in a highland Peruvian Indian population. M.A. Thesis, Pennsylvania State University, University Park, Pennsylvania.

Hunt, E. E., Jr. 1966 The developmental genetics of man. In: Human Development. F. Falker, ed. Saunders, Philadelphia and London, pp. 76-122. 
Jelliffe, E. R. P., and D. B. Jelliffe, eds. 1969 The arm circumference as a public health index of protein-calorie malnutrition of early childhood. J. Trop. Pediat., 15: 176-260.

Malcolm, L. A. 1969 Growth and development of the Kaiapit children of the Markham Valley, New Guinea. Am. J. Phys. Anthrop., 31: 39-51. 1970 Growth and development of the Bundi child of the New Guinea Highlands. Human Biol., 42: 293-328.

Mangin, W. 1967 Squatter settlements. Scientific Amer, , 217: 21-29.

Pollitt, E., and H. Ricciuti 1969 Biological and social correlates of stature among children in the slums of Lima, Peru. Amer. J. Orthopsychiatry, 39: 735-747.

Schrimshaw, N. S., and J. E. Gordon 1968 Malnutrition, Learning, and Behavior. N. S. Scrimshaw and J. E. Gordon, eds. The M.I.T. Press, Cambridge, Massachusetts, and London, England.

Stini, W. A. 1972a Malnutrition, body size and proportion. Ecol. of Food and Nutrition, 1: 121-126.

1972b Reduced sexual dimorphism in upper arm muscle circumference associated with protein-deficient diet in a South American population. Am. J. Phys. Anthrop., 36: 341-351.
Thomas, R. B. 1972 Human adaptation to a high Andean energy flow system. Ph.D. Thesis, Pennsylvania State University, University Park, Pennsylvania.

Thompson, A. M. 1966 Adult stature. In: Somatic growth of the Child. J. J. Van der Werff, T. Bosch and A. Hask, eds., Charles C Thomas, Springfield, Illinois.

Thompson, A. M., and W. Z. Belewicz 1963 Nutritional status, maternal physique, and reproductive efficiency. Proc. of the Nutrition Society, 22: 55-60.

Weiner, J. S., and J. A. Lourie 1969 Human Biology. A Guide to Field Methods. Blackwell, Oxford.

Widdowson, E. M. 1968 The place of experimental animals in the study of human malnutrition. In: Calorie deficiencies and protein deficiencies. R. A. McCance and E. M. Widdowson eds. The M.I.T. Press, Cambridge, Massachusetts, and London, England.

Wolanski, N. 1970 Genetic and ecological factors in human growth. Human Biol., 42: 349 368.

Yerushalmy, J., B. J. Berg, C. L. Erhardt and H. Jacobziner 1965 Birth weight and gestation as indices of "immaturity." Amer. J Diseases Children, 109:43-57. 